\title{
The Existence of The Definite Integral: Students' Understanding
}

\author{
Christina Kartika Sari ${ }^{1}$, Isnaeni Umi Machromah ${ }^{2}$, Nida Sri Utami ${ }^{3}$, Zakiyyah ${ }^{4}$ \\ \{christina.k.sari@ums.ac.id ${ }^{1}$, isnaeniumi@ums.ac.id ${ }^{2}$, nida.utami@ums.ac.id ${ }^{3}$. \\ a410180231@students.ums.ac.id $\left.{ }^{4}\right\}$
}

Mathematics Education Department, Universitas Muhammadiyah Surakarta, Indonesia ${ }^{1234}$

\begin{abstract}
The definite integral is a part of a compulsory subject, Integral Calculus, for mathematics education students. As pre-service mathematics teachers, students' understanding of the definite integral concepts is crucial to note. This article presents the result of the investigation students' understanding of the definition of the definite integral and its existence. The study reported in this paper was done through qualitative research. A questionnaire about the definition of the definite integral and the existence of the definite integral of a defined function on a closed interval was given to 163 students who took Integral Calculus course. Then, 4 of them were selected to interview in depth. The students' responses indicated the diversity of the conceptual understanding of the existence of the definite integral. Various students' understanding of the definition of the definite integral that leads to students' understanding of the existence of the definite integral is presented as well.
\end{abstract}

Keywords: calculus, conceptual understanding, the definite integral, students' understanding

\section{Introduction}

When students meet calculus, students learn some basics of mathematics, such as function, limit, and integral [1]. This is a mandatory course to study in Science, Technology, Engineering, or Mathematics (STEM) [1][2] [3]. Therefore, calculus is considered as a crucial course to master [2] [4]. In fact, calculus is one of a difficult part in mathematics, no exception to the integral. The conceptual understanding of integral is considered as one of the causes why students have to struggle to pass this course [4].

Calculus is not a completely new course for undergraduate students, because they dealt with it in their secondary school [5] [6] [7]. This is still the compulsory subject for students who study in the mathematics education department. After students face with limits of function and derivative, students learn integral calculus. Students presume that calculating integral is the greatest goal in learning integral [2] so that they neglect the formal definition. They focus on how to calculate like the teacher's examples, do their task, and miss the meaning of the problems that they solved [8]. Whereas the definite integral is considered as an essential concept to solve the problem in Calculus [9].

In secondary school, curricula focus on evaluating the definite and indefinite integral, and using integral in some applications, such as in finding area. Teachers in secondary schools do not stress the definition of integral. Students neglect the conceptual understanding and focus on the 
procedural concept [10]. Like in limits and continuity which students have their concept image [11], students also have some concepts on integral that differ from the formal definition. It is hard for students to learn the abstract concept when they face it in the first undergraduate year [12]. The formal definition of the definite integral is systematically learnt in this undergraduate year [13].

At the beginning of the definite integral course, the class was started by watching a video about Riemann Sum and how to lead it to the definition of the definite integral. In their book, Varberg, Purcell, and Rigdon [14] state if $f$ be a function that is defined on closed interval $[a, b]$ then the definite integral of $f$ from $a$ to $b$, is given by:

$$
\int_{a}^{b} f(x) d x=\lim _{|P| \rightarrow 0} \sum_{i=1}^{n} f\left(\bar{x}_{\imath}\right) \Delta x_{i}
$$

where $P$ is a partition of the interval $[a, b]$ into $n$ subintervals and $\overline{x_{l}}$ is an arbitrary point in each subinterval $\left[x_{i-1}, x_{i}\right]$.

Though there are some point of view to define the definite integral, such as: a computation, an area, a summation, a total change from $x=a$ to $x=b$, a function, or an abstract object, the central point is the limit of summing process [15]. Range [16] state that integral is the limit of approximating sum. The problem related to finding area leads to the concept of the definite integral [14][16]. Before students learn the definite integral, students have studied about the indefinite integral. In Calculus, Fundamental Calculus Theorem becomes the bridge of the indefinite integral and definite integral. Based on Varberg, Purcell, and Rigdon [14], the theorem says that if $f$ be a continuous function on $[a, b]$ and $F$ be an antiderivative of $f$ on $[a, b]$, then

$$
\int_{a}^{b} f(x) d x=F(b)-F(a)
$$

This theorem usually used to solve problems related to the definite integral. Not surprising that students consider that The Fundamental Theorem of Calculus as a definition of the definite integral. In the first meeting on the definite integral class, this understanding arisen on students' understanding of the definition of integral.

The latter theorem is what students' usually answer when they face with a question about the definite integral. On the first meeting in studying the definite integral, though the concept of limit of approximating sum is essential for the definite integral [16], there were no students who mentioned the concept of limit. Based on the questions that usually given to provoke students' understanding, students' answer indicated the lack of students' understanding of the definition of the definite integral. Besides, students seemed to neglect the guarantee of the existence of the definite integral before they calculate it. However many papers propose students' understanding of the definition of definite integral or the difficulties, fewer papers explain students' understanding of the existence of the definite integral. This paper presents students' understanding of the definite of integral and its existence. 


\section{Methods}

\subsection{Participants}

The presented paper is based on the results of 163 students' work in answering a questionnaire of the definite integral. They were pre-service mathematics students who took Integral Calculus course. The questionnaire was given at the end of the semester so that students have learnt the definite integral and its characteristics. Based on the results of questionnaire, purposive sampling approach was done to choose subjects of this research.

\subsection{Questionnaire}

The questionnaire was designed to gain students' perception of the definition of definite integral and its existence. The questionnaire consists of three questions. The first is about the definition of $\int_{a}^{b} f(x) d x$, the second asks students to explain about the existence of the definite integral function $f$ from $a$ to $b$. The last is a question about the existence of $\int_{a}^{b} f(x) d x$, where $f$ is a discontinuous function in a point of $(a, b)$. The questionnaire is presented in Fig.1.

1. Jelaskan definisi dari $\int_{a}^{b} f(x) d x$ ?

2. Misalkan $f$ fungsi yang terdefinisi pada $[a, b]$. Apakah kita selalu dapat menemukan nilai dari $\int_{a}^{b} f(x) d x$ ? Jelaskan.

3. Perhatikan gambar berikut ini.

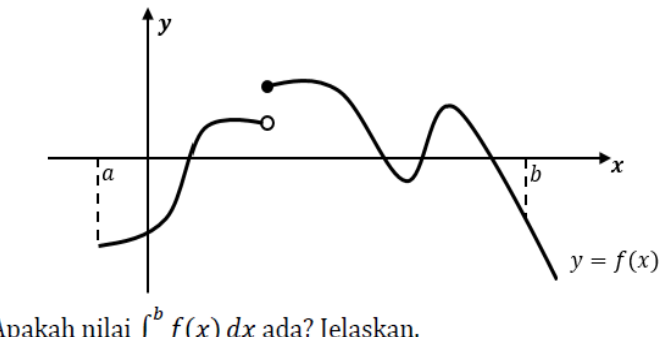

Fig. 1. The questionnaire

The first question was proposed to capture students' understanding of the definition of the definite integral. This question also used by [5] . Question 2 was designed to find out students' perception of the existence of the definite integral $f:[a, b] \rightarrow \mathbb{R}$, where $\mathbb{R}$ is a real number system. This question also enriches data about students' understanding of the definite integral. The last question was proposed to check students' understanding on the existence of definite integral function $f$ from $a$ to $b$. Question 3 was considered to confirm students' perception about the definition of definite integral for a discontinuous function on a point in $[a, b]$ and its characteristics. Before this questionnaire was used to gain data, this was validated by two mathematics education lecturers who have a background in lecturing Calculus.

\subsection{Triangulation}

The method triangulation was done to gain valid data. Based on these results of the questionnaire, four students were selected to get more rich data about students' understanding on definition of definite integral and the existence of definite integral. These four students have 
different type in response to the questionnaire. For instance, these four students are called Alpha, Beta, Gamma, and Delta, then the symbol of $I$ means the interviewer. They were interviewed in depth to confirm their answers and to delve further information.

\section{Findings and Discussion}

First, this paper proposes the brief students' understanding on the definition of $\int_{a}^{b} f(x) d x$ and the existence of definite integral based on 163 student's responses. Further, some analysis were done to capture students' understanding in detail and to find out some facts or misconceptions.

\subsection{The definition of $\int_{a}^{b} f(x) d x$}

As many as 163 students' answers were analyzed to capture students' understanding of the definition of $\int_{a}^{b} f(x) d x$. The result are summarized in Table 1 as follows.

Table 1. Students' Responses on The Definition of The Definite Integral

\begin{tabular}{lll}
\hline $\begin{array}{l}\text { Students' responses about the definition of the } \\
\text { definite integral }\end{array}$ & \multicolumn{2}{c}{ The number of students' responses } \\
\cline { 2 - 3 } & Quantity & 1.23 \\
\hline Limit of Riemann sum & 2 & 1.84 \\
Tried to state limit of Riemann sum but failed & 3 & 23.93 \\
The Fundamental Theorem of Calculus & 39 & 8.59 \\
Incorrect The Fundamental Theorem of Calculus & 14 & 35.58 \\
Only read the symbol of $\int_{a}^{b} f(x) d x$ & 58 & 8.59 \\
The sum of polygons bounded by $f, x=a$ and $x=b$ & 14 & 4.29 \\
The sum of the area under the function & 7 & 1.23 \\
Wrote response with keyword "increase function & 2 & 2.45 \\
Anti-derivative of $f$ & 4 & 12.27 \\
The deviant responses & 20 & 100 \\
\hline Total & 163 & \\
\hline
\end{tabular}

According to Table 1, many students have conceptual understanding that deviates with the formal definition. Only $9.82 \%$ students answered correct way by stated about the limit of Riemann sum and the sum of polygons bounded by $f, x=a$ and $x=b$. As stated by Range [16], the limit is essential to the definition of definite integral. The lack of this limit concept leads to students' misconception on the definite of integral [10].

There are 53 students who have concept image the definite integral is associated with The Fundamental Theorem of Calculus. According to Radmehr and Drake [17], most of thr students considered that $\int_{a}^{b} f d x=F(b)-F(a)$ used to calculate the area under the function of $f$ from 
$a$ to $b$. In this study, 14 of 163 students stated that the theorem incorrect, for example, Alpha. Alpha wrote the definition of $\int_{a}^{b} f(x) d x$ as follows.

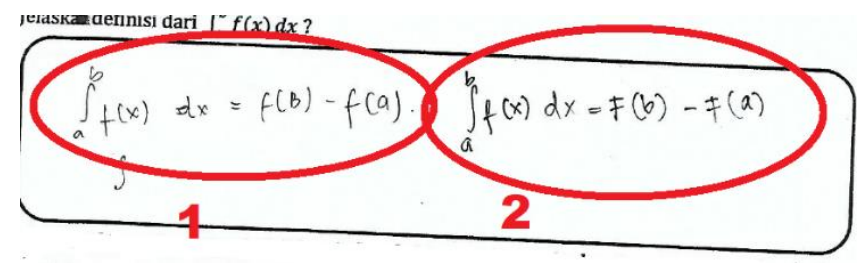

Fig. 2. Alpha's answer in defined the definite integral

Part 1 on the Fig. 2. is what Alpha wrote on his questionnaire. Alpha's first opinion about $\int_{a}^{b} f(x) d x$ is $f(B)-f(a)$. This form is nearly close to Fundamental Theorem of Calculus. However, it has to underline that Alpha wrote function $f$, not the antiderivative of $f$. An interview was done to confirm Alpha's answer. An excerpt of it is stated as follows.

I : We agree that this (showed $\left.\int_{a}^{b} f(x) d x\right)$ is the symbol of the definite integral of $f$ from a to $b$. Then, what is the definition of the definite integral of $f$ from $a$ to $b$ or we symbolized as $\int_{a}^{b} f(x) d x$

Alpha : At first, I remembered this was $f(b)-f(a)$ but I read again, we had to do integration at first. So this is not what I mean.

$I \quad:$ So what is the definition of the definite integral of $f$ from $a$ to $b$ ?

Alpha: This (showed $f(b)-f(a)$ ) have not done by integration. First, we have to do integration on $f$ then we tested the points

I : So what is the definition?

Alpha : (wrote Part 2 on Fig.2)

$I \quad$ : What is F?

Alpha: $F$ is the function of $f(x)$ after we did integration

$I \quad:$ Is it the definition? (showed Part 2 on Fig.2)

Alpha: Yes

Students usually ignore the difference between two distinct objects. For example in writing $f$ and $F, x$ and $X, a \in A$ and $a \subseteq A$. This seems paltry, but in mathematics, this is fateful because they have a different meaning. However, from the conversation, it is clear that Alpha's understanding of the definition of $\int_{a}^{b} f(x) d x$ tend to Fundamental Theorem of Calculus. However Alpha never said that $F$ is an anti-derivative of $f$, term "the function of $f(x)$ after we did integration" directs to anti-derivative of $f$. This is Alpha's concept image about the definition of the definite integral. This concept appears through students' experiences [11]. The hypotheses is Alpha's concept image grew because Alpha usually the problems of definite integration that Alpha faced is calculation, such as evaluating the value of definite integral or some applications of integral.

The interesting response also appears from Beta's answer. Beta gave an opinion that the definition of the definite integral is similar to Fundamental Theorem of Calculus. It is clear from the Fig.3. that Beta wrote "function $F(x)$ increases its degree then substitutes the bound". 


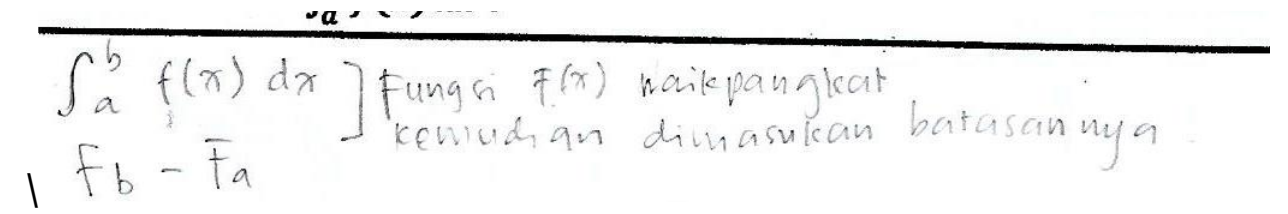

Fig. 3. Beta's opinion about the definition of definite integral

Betha stated the Fundamental Theorem of Calculus well by writing $\int_{a}^{b} f(x) d x=F(b)-$ $F(a)$, but Betha did not mention any hypotheses of the theorem. This theorem works on continuous function [14]. Besides, Betha also wrote the degree of $f$ increase. The piece of the interview about this part can be seen as follows.

I : We agree that this (showed $\int_{a}^{b} f(x) d x$ ) is the symbol of the definite integral of $f$ from a to $b$. Then, what is the definition of the definite integral of $f$ from $a$ to $b$ or we symbolized as $\int_{a}^{b} f(x) d x$

Betha : In my opinion... (silent for a moment) function of $f(x)$ is... Oh, it's hard to explain. The point is that $f(x)$ is anti-derivative

I : $f$ or $F$

Betha : $\quad$ This (referred to $F$ )

I : Okay

Betha : F is anti-derivative, we increased the degree, and then we substituted defined bound as the substitution of variable

From Betha's response on the last part, it is obvious that Betha's understanding about the definite integral is the Fundamental Theorem of Calculus and Beta associated $F$ anti-derivative with the term "increase the degree of function". Though Beta seemed hard to say in Beta own word, Beta looked to use The Fundamental theorem of Calculus. In line with Denbel, students feel difficult to say their conceptual understanding of their word [18].

The similar response was given by Gamma. From Fig. 4, Gamma declared that the integral of function is "increase the function".

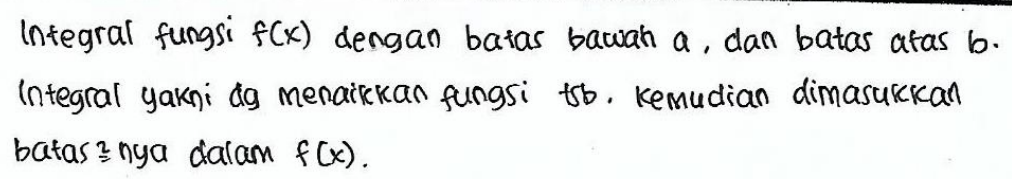

Fig. 4. Gamma's answer on the definition of the definite integral

An interview was done to confirm what Gamma stated. The first, Gamma mentioned an interesting term, the general integral. According to Gamma, the general integral is like a general function but it is increased. The excerpt of Gamma's interview can be seen as follows.

I : We agree that this (showed $\int_{a}^{b} f(x) d x$ ) is the symbol of the definite integral of $f$ from a to $b$. Then, what is the definition of the definite integral of $f$ from a to $b$ or we symbolized as $\int_{a}^{b} f(x) d x$

Gamma: The definite integral is like the general integral, but it is like space, there is upper bound and lower bound.

I : It is like the general integral. What do you mean by the general integral?

Gamma: The general integral is like a general function but if it is integral, it is increased 


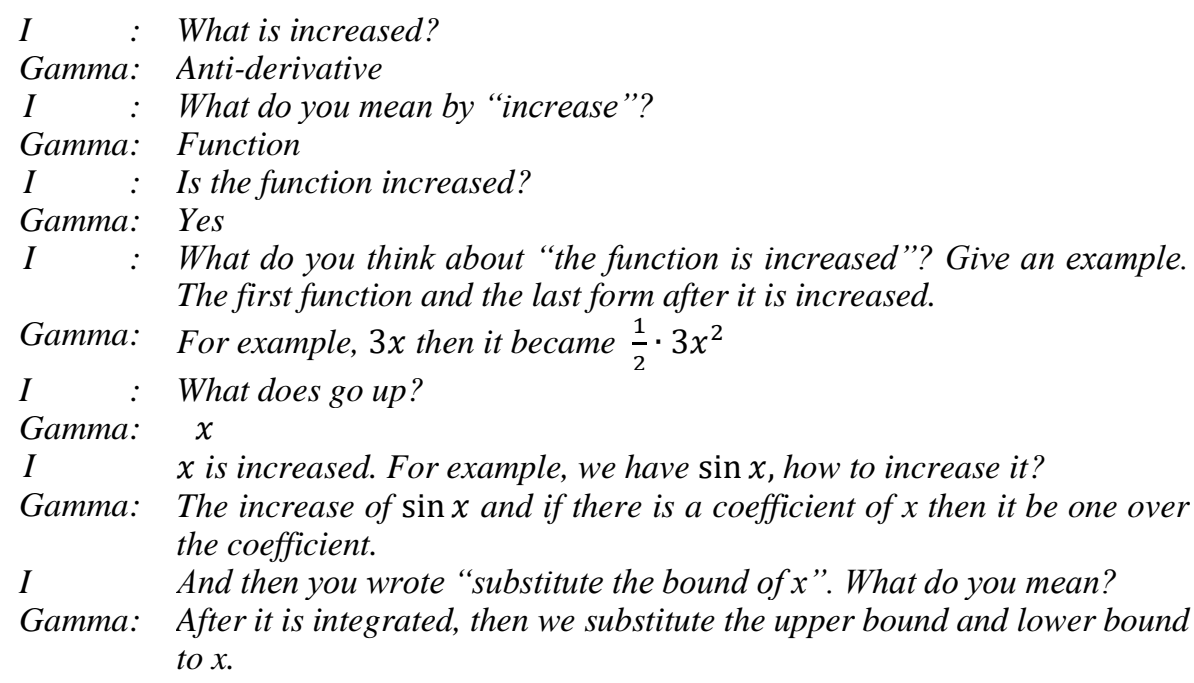

As stated in the excerpt, Gamma gave an example of the increased function by saying $3 x$ then it became $\frac{1}{2} \cdot 3 x^{2}$. Moreover, when Gamma was asked about another case of function, $\sin x$, Gamma told the increase of $\sin x$ and said that "if there is a coefficient of $x$ then it be one over the coefficient". What Gamma mentioned is like the theorem related integral of algebraic functions, or it is called Theorem of Power Rule [14], that is:

$$
\int a x^{n} d x=\frac{a}{n+1} x^{n+1}
$$

where $n$ is any rational number and $n \neq-1$. Gamma looks difficult to state the concept image in Gamma own words [18]. According to Gamma, the integral of function is the increase of function that related to the Theorem of Power Rule. Gamma's concept image thought to appear because Theorem of Power Rule is oftentimes used in solving the integral problems. This theorem is a great tool to solve the definite integral [14]. Gamma's experience leads to this concept image about the definite integral [11].

Other interesting responses also seem written by many students. Even though students were emphasized to write their understanding of the definition of definite integral, the majority of students left their questionnaire by only read the symbol $\int_{a}^{b} f(x)$ without any explanations. One of them is Delta. Fig. 5. depicts Delta's response when he was asked about the definition of $\int_{a}^{b} f(x) d x$.

$$
\text { Integral dan fungsi } x \text { dengan batasan dari a sampai } b
$$

Fig. 5. Delta's response on the definition of the definite integral

An interview was done to verify Delta's response. The following excerpt is Delta's confirmation about the definition of the definite integral.

I : We agree that this (showed $\int_{a}^{b} f(x) d x$ ) is the symbol of the definite integral of $f$ from a to $b$. Then, what is the definition of the definite integral of $f$ from a to $b$ or we symbolized as $\int_{a}^{b} f(x) d x$ 


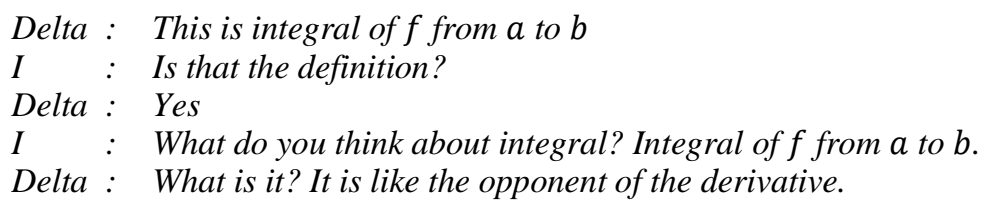

The first, Delta stated the definition of the definite integral was similar to Delta's written response by reading the symbol of the definite integral. However, when Delta was asked what is integral, Delta stated that integral is like the opponent of the derivative. Varberg, Purcell, and Rigdon [14] state that indefinite integral is anti-derivative, and the definite integral is the limit of Riemann sum. Though, there is The Fundamental Theorem of Calculus that evaluate the definite integral by using indefinite integral, these two kinds of integrals are a different concept.

\subsection{The existence of definite integral}

Question 2 and Question 3 delved students' understanding of the existence of the definite integral. Table 2 shows students' response about the existence of the definite integral of a defined function on $[a, b]$.

Table 2. Students' responses about the existence of definite integral of the defined function on $a, b]$

\begin{tabular}{|c|c|c|}
\hline \multirow[t]{2}{*}{ Students' reasons about the existence of the definite integral } & \multicolumn{2}{|c|}{$\begin{array}{l}\text { The number of students' } \\
\text { responses }\end{array}$} \\
\hline & Quantity & $\%$ \\
\hline \multicolumn{3}{|l|}{ The definite integral exists } \\
\hline The Fundamental Theorem of Calculus & 24 & 14.72 \\
\hline The function has bounds on $[a, b]$ & 37 & 22.70 \\
\hline The function is defined on $[a, b]$ & 26 & 15.74 \\
\hline Without reason or other deviant reasons & 55 & 33.74 \\
\hline \multicolumn{3}{|l|}{ The definite integral does not necessarily exist } \\
\hline Depending on the function & 6 & 3.68 \\
\hline The sum of polygons can be infinity & 1 & 0.61 \\
\hline $\begin{array}{l}\text { The integral concept is "almost close to" so there is no guarantee } \\
\text { the existence }\end{array}$ & 1 & 0.61 \\
\hline It can be a discontinuous function & 2 & 1.23 \\
\hline Without reason or other deviant reasons & 5 & 3.07 \\
\hline Blank & 6 & 3.68 \\
\hline Total & 163 & 100 \\
\hline
\end{tabular}

At a glance, the majority of students consider that the definite integral of the defined function on $[a, b]$ always exists. The argumentations come from some perspectives. A $33.74 \%$ of students argued that the definite integral exists but they left without reason, wrote less logical reasons or even deviant reasons, such as because integral has characteristics or the value of function increases. Further, Beta's responses can be delved to gain more information about this case. 


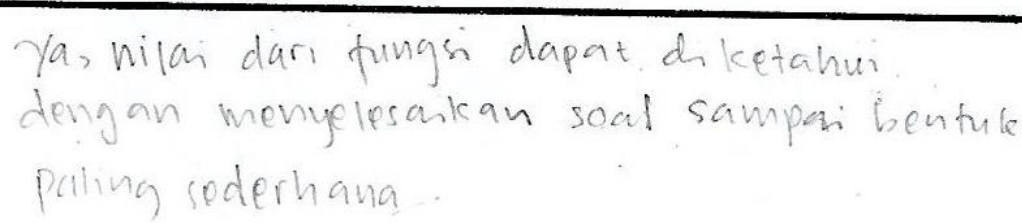

Fig. 6. Beta's response to the existence of integral

From Fig. 6, Beta stated that the value could be known by solving the question to the simplest form. This statement is supported by the following excerpt.

I : (Gave an introduction of Question 2) Then, does this definite integral always exist?

Betha : Yes

I : Why?

Betha : Because.... (took a long time)

I : In your work, you wrote "finishing until the simplest form", what does it mean?

Betha : From the question, function of $f(x)$, then it is solved the its integration until... the degree increased.

I : Do you mean that integral is the degree increased?

Betha : Yes. So.... (took a long time to respond)

I : Do you think that all functions always be found the simple value or be increased their degree?

Betha : Yes

I : Is that so?

Betha: Of course

According to Beta, all function could be integrated by increasing the degree and this value always exists. The same response was given by Gamma.

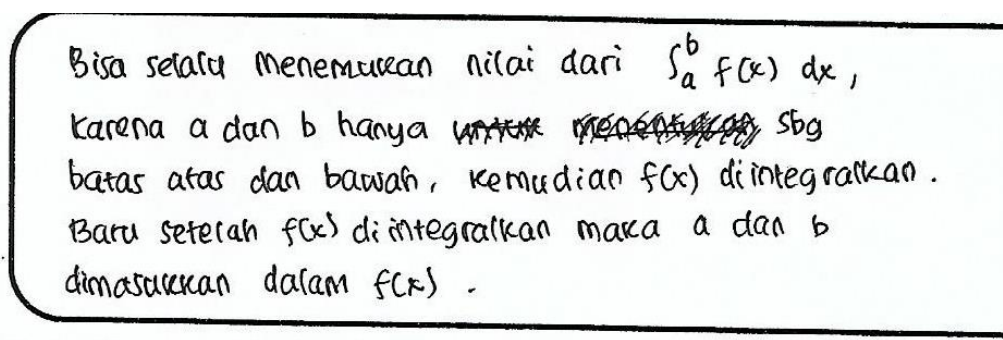

Fig. 7. Gamma's answer on Question 2

I : (Gave an introduction of Question 2) Then, does this definite integral always exist?

Gamma: Yes

I : Why

Gamma: Because integral is always "increased". Every function has its increase, so there is always its coefficient of $x$.

In the last sentence of the excerpt above, Gamma called integral of function as the increase of function. This Gamma's conceptual understanding appears because the indefinite integral is considered as derivative (in Bahasa, it is called "turunan", that means the decrease). 
It is interesting to note from Table 2 that $14.72 \%$ of students stated that the definite integral of function $f$ on $[a, b]$ exists because of The Fundamental Theorem of Calculus. This theorem offers the connection between the area enclosed by continuous functions and their antiderivatives [19]. Most of the students, in this case, stated the theorem without any argumentation about continuous function.

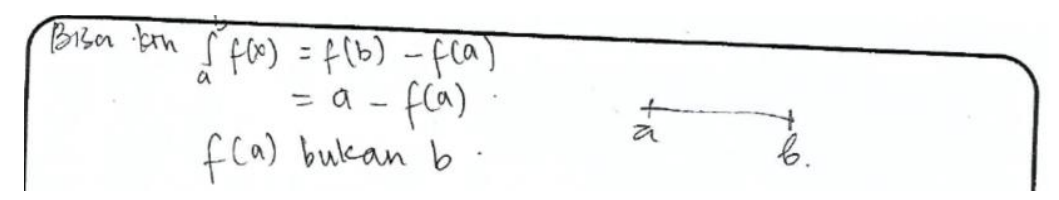

Fig. 8. Alpha's response to Question 2

At a glance, from Fig. 8, it seems interesting why Alpha changed $f(b)$ into $a$ then Alpha wrote " $f(a)$ is not $b "$. Based on clarification, Alpha thought that $[a, b]$ means the value of $f$ in $a$ is $b$ or $f(a)=b$. This statement contradicts with what Alpha wrote. It seems that Alpha misunderstood about the symbol of a closed interval $[a, b]$ as a point $(a, b)$, so that Alpha said that $f(a)=b$. After it is clear, Alpha tried to answer the existence of definite integral as follows.

I : It is the defined function on closed interval $[a, b]$. Does the definite integral from a to b always exist?

Alpha : From a to $b$, the value of $f$ always exists. This means if we find the value of integral, it always exists.

I : Does that guarantee the existence?

Alpha: Yes

According to Alpha, $\int_{a}^{b} f(x) d x$ exists because function $f$ is defined on $[a, b]$. This reason only restated the hypotheses of Question 2. The similar answer was given by Delta as in the following picture.

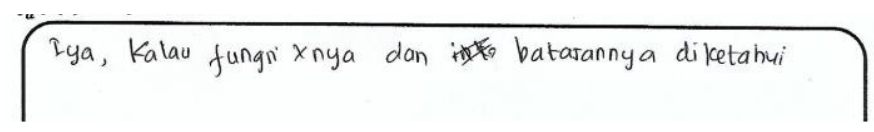

Fig. 9. Delta's answer in Question 2.

$I \quad$ : Do you think that the definite integral of $f$ from a to $b$ always exist?

Delta : Yes. When the bounds and the function exist.

I : If the function is defined on $[a, b]$, do the definite integral always exist?

Delta : Of course, when the function is defined.

I : Why?

Delta : When we calculate integral, the bound and function must be exist.

As stated by Delta, the existence of function and bounds (this means the function defined on $[a, b])$ guarantee the existence of its definite integral. According to Varberg, Purcell, and Rigdon $[14]$, not every defined function on $[a, b]$ is integrable on $[a, b]$. For example, the unbounded function $[a, b]$. However, there are $22.70 \%$ students wrote about the possibility of the unbounded function, students considered this possibility lead to the absence of the definite integral on $[a, b]$. 


\subsection{The existence of the definite integral of a jump discontinuous function on $[a, b]$}

Question 3 was given to delve students' understanding of the existence of the definite integral of a piecewise function as mentioned in Fig. 1. In response to this question, Beta stated that the definite exists. Beta guaranteed the answer by writing a formula given in Fig. 10 as follows.

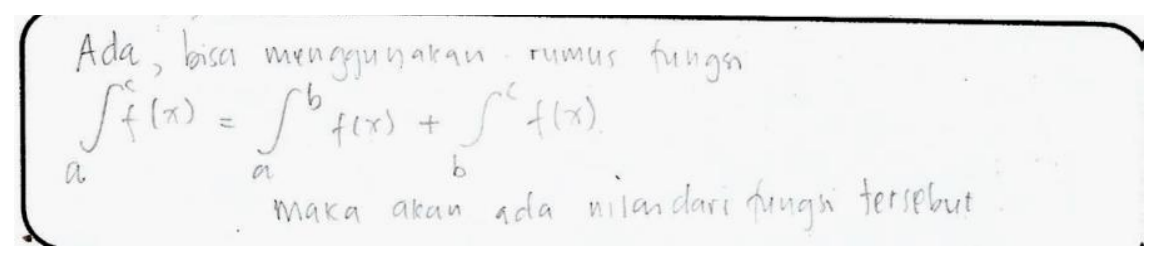

Fig. 10. Beta's answer in Question 3

At a glance, what Beta wrote is like Interval Additive Property. However, Beta stated a formula about $\int_{a}^{c} f(x) d x, \operatorname{not} \int_{a}^{b} f(x) d x$.

I : We have a function with its graph is like this [showed the graph in Question 3]. You wrote that the definite integral exists, why? What formula did you write? (showed Betha's answer).

Betha : The bounds in this [showed Betha's answer]. From a to $b$, suppose that this point is zero [showed the discontinuous point].

I : Where is zero?

Betha : Eh... (took a long time to respond)

I : In your answer, why did you wrote $c$ ? What is $c$ ?

Betha: Oh, the question is from a to $b$. Why did I write c?

$I \quad:$ Okay. The question is the definite integral from a to $b$. What do you think about it?

Betha : This can be divided into a to "this" and from "this" to b. (Betha referred the term "this" to the discontinuous point). It can be simplified.

I : Do you think that the value always exist?

Betha : Of course, it exists

An excerpt of an in-depth interview shows that Beta tried to divide the closed interval $[a, b]$ into two sub-intervals, namely $[a, c]$ and $[c, b]$, where $c$ is a discontinuous point. Then Beta calculated the definite integral by "simplifying" the function. Though the conceptual understanding of solving definite integral is incorrect, what Beta want to say is Interval Additive Property.

Meanwhile, in response to Question 3 and in an excerpt of the interview, Alpha mentioned that the definite integral does not exist because of the disconnected graph.

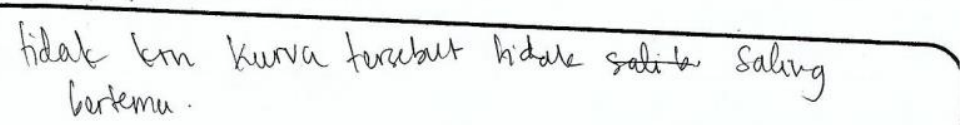

Fig. 11. Alpha's response to Question 3

I : Now, you can see Question 3. Does the definite integral exist?

Alpha : In my opinion, if it is from a to $b$, the definite integral does not exists because the graph is disconnected. However, the definite integral exists if it is from a to the disconnected point, then from $b$ to the disconnected point. 

I : If the question is like this (referred to $\int_{a}^{b} f(x) d x$ ), does the definite integral exist?

Alpha : No, it does not.

The same response also given by Delta. Fig. 12 depicts Delta's answer in Question 3.

$$
\text { Tidale ada, karena fungsi berbeda }
$$

Fig. 12. Delta's answer on Question 3

Delta wrote that the definite integral does not exist because it is a different function. Through an interview, Delta explained that the curve in Question 3 consists of two functions so that the definite integral failed to calculate. The excerpt interview related to this condition is given as follows.

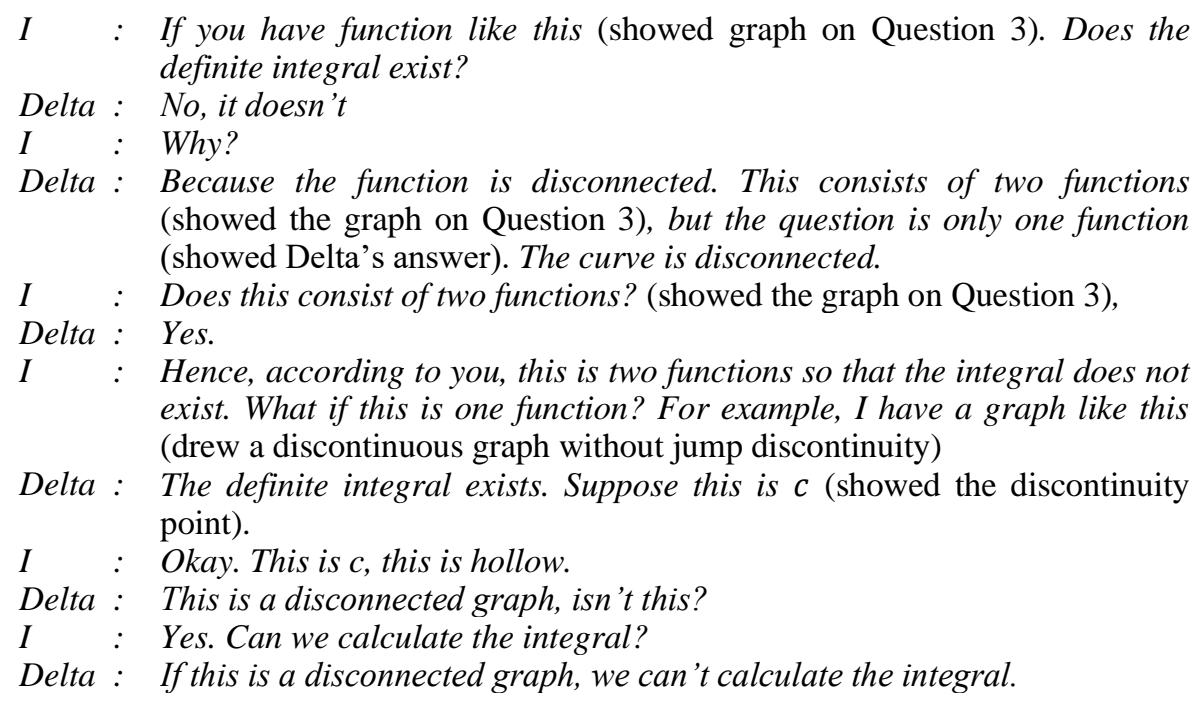

Delta could explain that if the curve does not have a jump discontinuity point, then the definite integral exists. However, when Delta faced with a graph with a jump discontinuity point, Delta stated that it is two functions. Hence the definite integral does not exist. Almost the same argumentation was produced by Gamma. However, Gamma concluded that the definite integral of the graph in Question 3 exists.

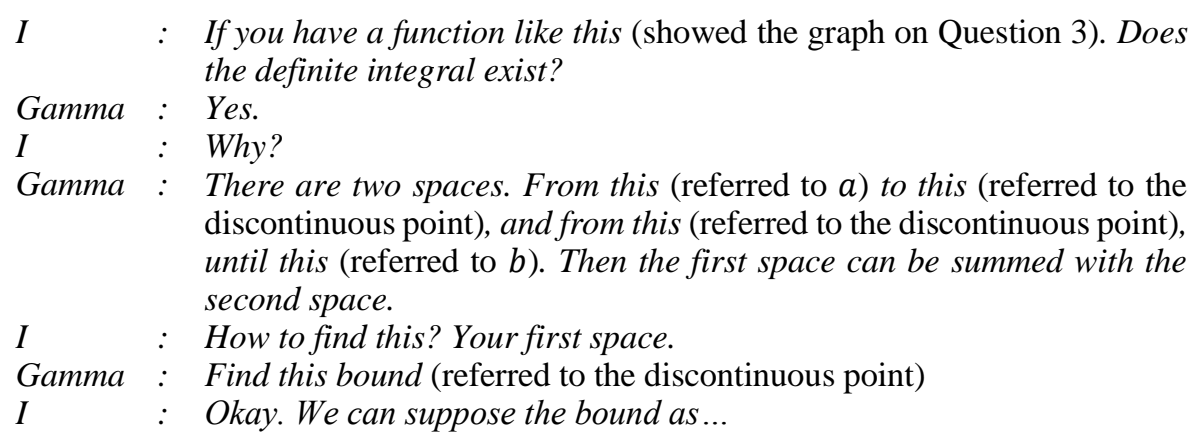




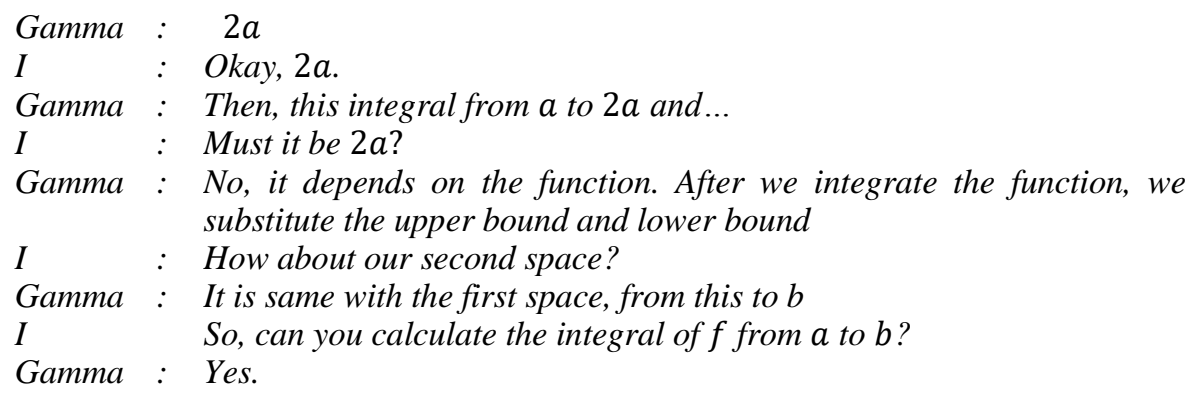

Though Alpha, Delta, and Gamma have a similar idea to solve the definite integral in Question 3 , by dividing into two part in its jump discontinuous point, they have a different conclusion about the existence of the definite integral. In line with Attorps et al [13], students meet difficulties in distinguishing the condition when they should use The Fundamental Theorem of Calculus.

The last, it is worth noting that based on Table 2, though 15 of 163 students argue that the definite integral does not necessarily exist, only 10 students stated the logical reason, such as the existence depends on the function, the sum of polygons can be infinity, the integral concept is "almost close to", and the possibility of discontinuous function that lead to the absence of the definite integral of its function. This condition reflects students' understanding of the definite integral has not to meet hope that pre-service mathematics teachers should discern the fundamental notion in definite integral. These errors finding in this study could be the background to support the calculus course instruction [20].

\section{Conclusion}

Many students who have a deviant understanding of the definition of the definite integral. In case they understand some concepts related to the definite integral, they cannot handle it to define the definite integral. Besides, some students consider the integral of function as the increase of function. There are various students' conceptual understanding of the existence of the definite integral. Some of them deviate from the formal concept. Most of the students guarantee the existence of the definite integral without a logical reason. Students work on The Fundamental Theorem of Calculus without regard to the hypotheses so that they failed to use it. In case of the definite integral of a piecewise function, though students have a great idea to solve it by using The Additive Rules, they cannot execute well.

Meaningful teaching and learning should be thought to support students' understanding of the definite integral. A teaching and learning program that emphasizes conceptual understanding, not only procedural understanding in solving integral problems.

\section{References}

[1] J. Ellis, M. L. Kelton, and C. Rasmussen, "Student perceptions of pedagogy and associated persistence in calculus," ZDM Mathematics Education, 2014.

[2] L. Aspinwall and L. D. Miller, "Students' Positive Reliance on Writing as a Process to Learn Firct Semester Calculus," Journal of Instructional Psychology, vol. 24, 1997.

[3] D. Serhan, "Students ' Understanding of the Definite Integral Concept," International Journal of Research in Education and Science (IJRES), vol. 1, no. 1, pp. 84-88, 2015. 
[4] N. Mahir, "Conceptual and procedural performance of undergraduate students in integration," International Journal of Mathematical Education in Science and Technology, vol. 40, no. 2, pp. 201-211, 2009.

[5] S. Rasslan and D. Tall, "Definitions and Images for the Definite Integral Concept," in Proceedings of the 26th Conference of the International Group for the Psychology of Mathematics Education, 2002, vol. 4, pp. 89-96.

[6] T. T. Lam, "On In-Service Mathematics Teachers' Content Knowledge of Calculus and Related Concepts," The Mathematics Educator, vol. 12, no. 1, pp. 69-86, 2009.

[7] D. Tall, "Students' Difficulties in Calculus," in Proceeding of ICME, 1993, no. August.

[8] N. Idris, "Enhancing students' understanding in calculus trough writing," International Electronic Journal of MathematicsEducation, vol. 4, no. 1, 2009.

[9] S. R. Jones, "The prevalence of area-under-a-curve and anti-derivative conceptions over Riemann sum-based conceptions in students' explanations of definite integrals," International Journal ofMathematical Education in Science and Technology, vol. 46, no. 5, pp. 721-736, 2015.

[10] S. E. Kiat, "Analysis of Students' Difficulties in Solving Integration Problems," The Mathematics Educator, vol. 9, no. 1, pp. 39-59, 2005.

[11] D. Tall and S. Vinner, "Concept image and concept definition in mathematics with particular reference to limits and continuity," Educational Studies in Mathematics, vol. 12, pp. 151-169, 1981.

[12] R. Gethner, "Definite Integration and the 'Need to Know' Principle," The Mathematics Teacher, vol. 108, no. 4, pp. 313-318, 2014.

[13] I. Attorps, M. Radic, and T. Tossavainen, "Varied ways to teach the definite integral concept," International Electronic Journal of Mathematics Education, vol. 8, no. May, pp. 82-99, 2013.

[14] D. Varberg, E. Purcell, and S. Rigdon, Calculus, 9th ed. Pearson Education, Inc., 2011.

[15] T. D. Oberg, "An investigation of undergraduate calculus students' conceptual understanding of the definite integral," The University of Montana, 2000.

[16] R. M. Range, "Where Are Limits Needed in Calculus ?," The American Mathematical Monthly, vol. 118, no. 5, pp. 404-417, 2011.

[17] F. Radmehr and M. Drake, "Exploring students' mathematical performance, metacognitive experiences and skills in relation to fundamental theorem of calculus," International Journal of Mathematical Education in Science and Technology, vol. 0, no. 0, pp. 1-29, 2017.

[18] D. G. Denbel, "Students' Misconceptions of the Limit Concept in a First Calculus Course," Journal of Education and Practice, vol. 5, no. 34, pp. 24-41, 2014.

[19] P. Taylor, A. Vajiac, and B. Vajiac, "Areas and the Fundamental Theorem of Calculus," International Journal of Mathematical Education in Science and Technology, vol. 38, no. 8, 2008.

[20] M. Y. Ting, "Definite Integral Automatic Analysis Mechanism Research and Development Using the 'Find the Area by Integration' Unit as an Example," EURASIA Journal of Mathematics Science and Technology Education, vol. 13, no. 7, pp. 2883-2896, 2017. 